\title{
Detecção de resíduos de antibióticos de leite UHT e leite in natura comercializado de forma informal em feiras e em mercados no município de Rolim de Moura - RO
}

\author{
Detection of antibiotic residues in UHT millk and in natura millk sold informally in fairs and \\ markets in the municipality of Rolim de Moura - RO \\ Detección de residuos de antibióticos en leche UHT y leche in natura comercializada informalmente \\ en ferias y mercados del municipio de Rolim de Moura - RO
}

Recebido: 14/10/2021 | Revisado: 22/10/2021 | Aceito: 05/02/2022 | Publicado: 06/02/2022

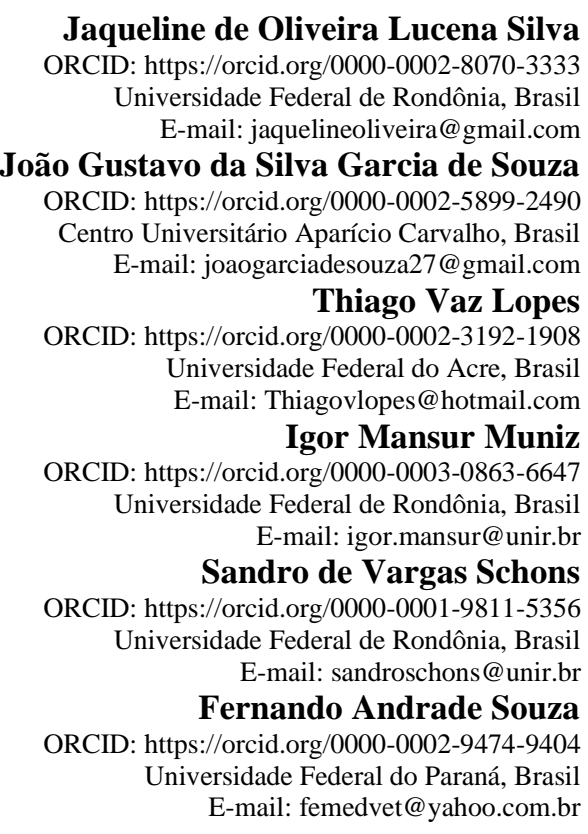

\begin{abstract}
Resumo
O leite é um dos produtos de origem animal mais consumidos no mundo devido seu alto valor nutritivo, é considerado um dos alimentos mais completos da natureza. Cerca de 20 a $30 \%$ da produção de leite bovino no Brasil é comercializado sem inspeção sanitária, ou tratamento térmico adequado. Este produto é denominado "leite informal" e é comercializado em utensílios plásticos ou de vidro elaborados para outros produtos, como refrigerantes. Apesar da irregularidade na comercialização do leite informal, são escassas as informações sobre a presença de microrganismos, toxinas, resíduos de antimicrobianos, contagens bacterianas totais e de células somáticas, bem como dos constituintes nutricionais e físico-químicos. A ausência de informações de qualidade deste produto expõe a população ao consumo de leite com baixa qualidade, aos riscos de reações orgânicas indesejáveis, além de veicularem toxinas e microrganismos com potencial zoonótico. Este trabalho teve o intuito de verificar a presença de resíduos de antibióticos em leite UHT e em leite comercializado de forma informal na cidade de Rolim de Moura, foram colhidas 99 amostras de leite sendo UHT, leite informal comercializado na feira comercial de Rolim de Moura e em estabelecimentos comercias de pequeno porte testadas pelo kit comercial Charm ${ }^{\circledR}$ Cowside II Test que utiliza o método colorimétrico, qualitativo para avaliar a presença de antibióticos em leite cru ou UHT. Das 99 amostras colhidas 17(17,17\%) foram consideradas positivas. A legislação brasileira regulamenta que os resíduos de antibióticos e outros agentes inibidores de crescimento microbiano devem estar ausentes. Mais estudos científicos que instituam uma pesquisa da qualidade dos produtos devem ser encorajados e programas de incentivo a qualidade do leite devem ser instituídos para que se produza leite com excelência em qualidade e se tenha um produto seguro para os consumidores.
\end{abstract}

Palavras-chave: Leite; Leite informal; Resíduos; Antibióticos; Rolim de Moura.

\section{Abstract}

Milk is one of the most consumed animal products in the world due to its high nutritional value, it is considered one of the most complete foods in nature. About 20 to $30 \%$ of the production of bovine milk in Brazil is marketed without 
sanitary inspection or adequate thermal treatment. This product is called "informal milk" and is sold in plastic or glass utensils made for other products, such as soft drinks. Despite the irregularity in the commercialization of informal milk, there is little information about the presence of microorganisms, toxins, antimicrobial residues, total bacterial and somatic cell counts, as well as nutritional and physicochemical constituents. The lack of information on the quality of this product exposes the population to the consumption of low quality milk, to the risk of undesirable organic reactions, in addition to conveying toxins and microorganisms with zoonotic potential. This study aimed to verify the presence of antibiotic residues in UHT milk and in milk sold informally in the city of Rolim de Moura. in small commercial establishments tested by the commercial kit Charm ${ }^{\circledR}$ Cowside II Test that uses the colorimetric, qualitative method to assess the presence of antibiotics in raw milk or UHT. Of the 99 samples collected, 17 (17.17\%) were considered positive. Brazilian legislation regulates that residues of antibiotics and other microbial growth inhibiting agents must be absent. More scientific studies that institute research on the quality of products must be encouraged and programs to encourage the quality of milk must be instituted in order to produce milk with excellence in quality and to have a safe product for consumers.

Keywords: Milk; Informal milk; Resídues; Antibiotic; Rolim de Moura.

\section{Resumen}

La leche es uno de los productos animales más consumidos en el mundo debido a su alto valor nutricional, se considera uno de los alimentos más completos de la naturaleza. Alrededor del 20 al 30\% de la producción de leche bovina en Brasil se comercializa sin inspección sanitaria ni tratamiento térmico adecuado. Este producto se llama "leche informal" y se vende en utensilios de plástico o vidrio hechos para otros productos, como refrescos. A pesar de la irregularidad en la comercialización de la leche informal, existe poca información sobre la presencia de microorganismos, toxinas, residuos de antimicrobianos, recuentos totales de células bacterianas y somáticas, así como constituyentes nutricionales y fisicoquímicos. La falta de información sobre la calidad de este producto expone a la población al consumo de leche de baja calidad, al riesgo de reacciones orgánicas indeseables, además de transmitir toxinas y microorganismos con potencial zoonótico. Este estudio tuvo como objetivo verificar la presencia de residuos de antibióticos en la leche UHT y en la leche que se vende informalmente en la ciudad de Rolim de Moura. En pequeños establecimientos comerciales probados por el kit comercial Charm ${ }^{\circledR}$ Cowside II Test que utiliza el método colorimétrico, cualitativo para evaluar la presencia de antibióticos en la leche cruda o UHT. De las 99 muestras recogidas, 17 (17,17\%) se consideraron positivas. La legislación brasileña regula la ausencia de residuos de antibióticos y otros agentes inhibidores del crecimiento microbiano. Se deben impulsar más estudios científicos que instituyan investigaciones sobre la calidad de los productos y se deben instituir programas para fomentar la calidad de la leche para producir leche con excelencia en calidad y tener un producto seguro para los consumidores.

Palabras clave: Leche; Leche informal; Desperdicio; Antibiótico; Rolim de Moura.

\section{Introdução}

A pecuária Leiteira permaneceu insignificante durante três séculos, apresentando significância a partir de 1870, época em que ocorreu um declínio da produção de café e teve maiores investimentos na pecuária leiteira. Em 1888, com a abolição da escravidão, a pecuária leiteira se expandiu e se difundiu nas regiões Sul e Nordeste, mas ainda caminhava lentamente nos quesitos tecnológicos. A partir da década de 1950 que coincidiu com fim da segunda revolução industrial do país que a atividade teve um avanço bem significativo. No ano de 1952 o presidente Getúlio Vargas assinou o decreto que aprovava o Regulamento de Inspeção Industrial de Produtos de Origem Animal que tornava a pasteurização do leite e a inspeção pelo S.I.F. (Sistema de Inspeção Federal) obrigatórios, de onde originaram outros atos normativos que padronizavam o leite produzido no Brasil aos internacionais possibilitando a exportação desse produto (Vilela et al. 2017).

O Brasil é o $5^{\circ}$ maior produtor de leite no nível internacional, o leite e um dos 6 produtos mais importantes para agropecuária no suprimento de alimentos, na geração de empregos e renda para a população. A produção leiteira em 2014 chegou a 35,17 bilhões de litros produzidos sendo a região Sul a maior produtora do país com 37\% do total Nacional. Mesmo aumentando a qualidade do leite e tentando igualar aos países que mais produzem o Brasil ainda é considerado um país de pouca produção leiteira (Jung \& Júnior, 2017).

Em 2014, a importação de lácteos somou US\$ 438,6 milhões e 106,8 mil toneladas, 25,1\% e 32,1\% valores menores comparados a 2013, respectivamente. Nos últimos anos, o Brasil importou produtos lácteos de 20 países, sendo que os principais países que exportaram para o Brasil foram Argentina e Uruguai, e os principais produtos importados foram leite em pó, soro em pó e queijo principalmente a muçarela. O produto mais exportado pelo Brasil nos últimos anos foi o leite integral em pó, com 
teor em peso de matérias gordas superior a 1,5\%, sem adição de açúcar ou de outros edulcorantes. Os valores por tonelada variaram entre US\$ 4,8 mil e US\$ 5,7mil. Em 2014, os principais produtos lácteos exportados além do leite em pó foram o leite condensado, outros leites, cremes e a manteiga. As exportações de leite em pó integral alcançaram 39,17 mil toneladas e trouxeram um rendimento de mais de US\$ 211 milhões de dólares, sendo provenientes de nove estados (MG, RS, SP, PR, ES, SC, GO, RO e RJ). A manteiga e similares foram exportados por seis estados, totalizando 5,8 milhões de toneladas e rendendo US\$ 22,6 mil dólares, ao preço médio de US\$ 3,9 mil dólares por tonelada. Outros leites e cremes (leite condensado) foram exportados por oito estados (MG, RS, SP, PR, MT, GO, RO e RJ) na quantidade de 28,3 milhões de toneladas, que renderam US\$ 64,1 mil dólares. A exportação de leite em pó representou 63,6\% das exportações de produtos lácteos, e as manteigas e similares, 6,79\%. O leite condensado, outros leites e cremes representaram 19,29\% dos valores das exportações (SEBRAE, 2015).

Na região Norte o estado tem produção de leite mais expressiva é Rondônia com $65 \%$ da produção de leite da região. Em Rondônia, Jaru e o município que mais produz leite, mas Rolim de Moura também é um município importante para essa crescente produção com uma produção de 15.237 litros de leite produzido. (IBGE, 2018).

A produção comercial de leite em Rondônia se iniciou na década de 70, em 1983 por iniciativa governamental foi aberta uma usina de leite intitulada Ouro Branco na cidade de Porto Velho e os produtores próximos a cidade começaram a fornecer leite para usina, pouco anos depois ela se expandiu abrindo uma outra usina em Ouro Preto do Oeste que era na época a cidade com maior produção leiteira e hoje em dia o estado já possui 38 mil novas industrias. Nos últimos anos, o parque industrial de Rondônia diversificou em variedade de produtos lácteos. A muçarela, principal produto, outros queijos, iogurte e manteiga são alguns dos produtos fabricados há vários anos. Atualmente, existem mais três fábricas que processam leite em pó e soro em pó, uma de soro em pó, duas de leite condensado, entre outros produtos. O leite processado em Rondônia é parcialmente consumido no estado, mas aproximadamente $75 \%$ é comercializado para outros estados, destacando os estados de São Paulo e Amazonas. Situação inversa de 30 anos atrás, quando o estado importava praticamente todos os produtos lácteos consumidos, pois a produção de leite era pequena, e o único produto lácteo era uma pequena quantidade de leite pasteurizado. Em 2013, o leite entregue aos laticínios aumentou em 1,76\% em relação ao ano anterior, para decrescer quase 3\% em 2014 (SEBRAE, 2015).

Ainda assim Rondônia e considerado um estado com baixa escala de produção de leite, isso ocorre por se tratar de um local onde há pouca aquisição de equipamentos para tecnificar o manejo, a forma de armazenamento e também o transporte desse leite para as indústrias, a falta dessas tecnologias torna o estado um ponto crítico pra qualidade do leite, mas já vem buscando melhores formas para aumentar a produção e a qualidade do produto um problema que vem sendo bem resolvido. Na propriedade uma alternativa pra melhorar a armazenagem até a indústria recolher esse leite, foi aderido à utilização de tanques de resfriamento em algumas propriedades que são compartilhados entre alguns produtores que ajudam a preservar a qualidade do leite produzido (EMBRAPA, 2014).

Entende-se por leite, sem outra especificação, o produto oriundo da ordenha completa, ininterrupta, em condições de higiene, de vacas sadias, bem alimentadas e descansadas (BRASIL, 2017). A lactação e o processo de produção e liberação do leite. Para que se produza um litro de leite, é necessária a passagem de 300 a 500 litros de sangue pelo úbere. A produção consiste na síntese do leite pelas células da glândula mamaria que secretam esse leite em cavidades dentro da glândula. A liberação ou ejeção do leite se dá através da expulsão desse leite armazenado nas cavidades da glândula mamaria para a boca do recémnascido (Hill et al., 2012).

Para compreender a lactação é necessário compreender que a glândula mamaria (figura 1) é uma glândula anexa do tegumento que se compõe de uma série de complexos mamários, em ruminantes a glândula mamaria se restringe a região inguinal e é denominada úbere. Cada complexo mamário consiste em uma ou mais unidades mamarias que possuem um corpo mamário e uma teta ou papila (König \& Liebich, 2016). O úbere dos bovinos constitui-se de quatro glândulas mamarias denominadas 
quartos, cada quarto e uma unidade separada dos outros três, cada um tem seu próprio sistema de secreção de leite. As unidades secretoras de leite da glândula mamária são pequenas estruturas denominadas alvéolos que são organizados semelhante a cachos de uvas ao redor de tubos. Cada alvéolo e um arranjo de células minúsculas em forma de um saco que secreta leite em um tubo igualmente pequeno chamado ducto alveolar (figura 2). Os pequenos ductos alveolares unem-se para formarem ductos maiores que desembocam em uma cavidade denominada seio glandular ou seio lactífero que fica localizada dorsalmente e acima da teta e faz continuidade com a cavidade da teta também denominada seio papilar que leva o leite secretado até o ducto papilar para ejeção do leite (Colville \& Bassert, 2010).

O leite possui um padrão de qualidade especificado pelo RIISPOA que determina que o leite deve possuir: características sensoriais (cor, odor e aspecto) normais, teor mínimo de gordura de 3,0g/100g, teor mínimo de proteína de 2,9g/100g, teor mínimo de lactose de 4,3g/100g, teor mínimo de sólidos não gordurosos de 8,4g/100g, teor mínimo de sólidos totais de $11,4 \mathrm{~g} / 100 \mathrm{~g}$, acidez titulável entre 0,14 e 0,18 expressa em gramas de ácido lático/100 mL, densidade relativa a $15^{\circ} \mathrm{C}$ entre 1,028 e 1,034 expressa em $\mathrm{g} / \mathrm{m}$, índice crioscópico entre $-0,530^{\circ} \mathrm{H}$ e $-0,555^{\circ} \mathrm{H}$, equivalentes a $-0,512^{\circ} \mathrm{C}$ e a $-0,536^{\circ} \mathrm{C}$, respectivamente, não apresente substâncias estranhas à sua composição, tais como agentes inibidores do crescimento microbiano, neutralizantes da acidez, reconstituintes da densidade ou do índice crioscópico e não apresente resíduos de produtos de uso veterinário e contaminantes acima dos limites máximos previstos em normas complementares (Brasil, 2017).

Algumas industrias utilizam testes para verificar a viabilidade do leite, esses testes devem assegurar que o leite está dentro dos parâmetros exigidos pela instrução normativa 77, os testes mais utilizados são o de contagem total de bactérias (CTB), contagem de células somáticas (CCS) e o de detecção de antibióticos (EMBRAPA, 2014).

Todos esses procedimentos são adotados pelas indústrias para prever um grande uso indiscriminado de substancias que deixam resíduos no leite e também para diminuir a disseminação de patógenos, devido à alta prevalência da doença infecto contagiosa conhecida por mastite bovina que interfere diretamente na qualidade do leite devido à alta prevalência no rebanho bovino leiteiro. A forma mais comum é a subclínica que apesar de não apresentar sintomatologia clínica representa uma grande importância epidemiológica por ser foco de transmissão para animais saudáveis (EMBRAPA, 2011).

$\mathrm{Na}$ incessante busca por um produto de qualidade em algumas regiões do Brasil foram instituídos programas para fiscalizar a presença de resíduos antibióticos no leite, o Programa de Análise de Resíduos de Medicamentos Veterinários em Alimentos de Origem Animal (Pamvet) foi desenvolvido pela Anvisa com o objetivo de operacionalizar sua competência legal de controlar e fiscalizar resíduos de medicamentos veterinários em alimentos, conforme determina o inciso II do parágrafo $1^{\circ}$ do Art. $8^{\circ}$ da Lei n. 9.782 de 26/01/1999. Esse programa visa ainda verificar ocorrência de resíduos de medicamentos veterinários em alimentos de origem animal avaliada visando estimar a exposição do consumidor a estes contaminantes, laboratórios da rede de saúde pública capacitados para desenvolver, otimizar, validar e implantar métodos de análise de resíduos de medicamentos veterinários, parâmetros definidos para a interpretação dos resultados de análise, inicialmente baseados em referências internacionais, avaliação de risco realizada com base científica a fim de subsidiar futuras ações de vigilância sanitária em relação ao controle de resíduos de medicamentos veterinários em alimentos, avaliação de se as boas práticas de uso de medicamentos veterinários estão sendo observadas possibilitando interagir com outros atores para a sua promoção. Banco de dados sobre resíduos de medicamentos veteriná-rios em alimentos no Brasil criado para disponibilizar informações à sociedade. Todos esses parâmetros avaliados pelo programa seriam muito necessários em regiões de pontos críticos como Rondônia, aumentaria a qualidade do leite produzido na região e também daria mais credibilidade e incentivo à produção de leite Rondoniense (ANVISA, 2009).

Um leite de qualidade depende unicamente da sanidade dos animais, da higiene no momento da ordenha tanto do ordenhador (manual ou mecânico) como também do animal e também do manejo para a prevenção de mastites (Almeida, 2016). 
O critério de inclusão de resíduos para monitoramento da qualidade de alimentos de origem animal em programas de diversos países é feito sob as seguintes condições: geração de resíduos pela substância; o grau de toxicidade do resíduo para a saúde do consumidor; o potencial de exposição da população ao resíduo (considerando-se hábitos alimentares, poder aquisitivo, tecnologia para a produção de alimentos para consumo animal), poluição ambiental; mau emprego das drogas formadoras de resíduos (com a consequente aplicação das boas práticas agrícolas e pecuárias); uso de metodologias adequadas para análise, que sejam confiáveis, exequíveis e compatíveis com os recursos laboratoriais existentes; implicações nas relações comerciais internacionais dos resíduos que possam constituir barreiras às exportações de alimentos de origem animal; e problemas que tragam risco à saúde pública (Martin, 2011).

O Limite Máximo de Resíduos (LMR) (figura 14) é a quantidade máxima de resíduos que resultam da utilização de um medicamento veterinário (expresso em $\mathrm{mg} / \mathrm{kg}, \mathrm{mg} / \mathrm{L}, \mu \mathrm{g} / \mathrm{kg}$ ou $\mu \mathrm{g} / \mathrm{L}$ de alimento) que se pode aceitar. Este limite baseia-se no tipo e quantidade de resíduos que não apresentam risco de toxicidade para a saúde humana, considerando a Ingestão Diária Aceitável (IDA). Os LMR também consideram as boas práticas veterinárias e levam em conta os resíduos presentes nos alimentos de origem vegetal e/ou no ambiente (ANVISA, 2009).

A mastite e uma doença que acomete a glândula mamária dos animais causando uma inflamação geralmente de caráter infeccioso, se apresenta na forma clínica e subclínica. Os principais agentes etiológicos causadores da mastite, são: Staphylococcus aureus, Streptococ-cus sp., Pseudomonas sp., Escherichia coli, Corynebacterium sp., Enterobacter, Proteus; Citrobacter, Klebsiella, Seratia, bacilos e algas do gênero Prototheca, entre muitas espécies de leveduras. Muitos microrganismos, dentre eles Staphylococcus aureus e algas do gênero Prototheca são responsáveis por causar mastite clínica de difícil tratamento (Gasparotto et al. 2016). A mastite é a doença mais prevalente economicamente entre os bovinos leiteiros em todos os continentes que causa muitos prejuízos para a comercialização e industrialização do leite por causar muitas alterações físico-químicas no produto e ainda representa um risco a saúde do consumidor devido a transmissão de patógenos e de suas toxinas e também pela presença de resíduos antibióticos usados indiscriminadamente para o tratamento desta injúria (Costa et al. 2013).

Segundo RIISPOA (Regulamento de Inspeção Industrial De Produtos De Origem Animal) é proibida a venda de leite que não esteja de acordo com suas características físico-químicas naturais, que apresentem resíduos de substancias estranhas a sua composição como medicamentos veterinários acima dos limites máximos exigidos (BRASIL, 2017). Resíduos de antibióticos podem ser encontrados no leite por introdução voluntária fraudulenta, para prolongar a durabilidade do produto ou por via indireta, oriunda do tratamento terapêutico de vacas em lactação com a utilização do leite destes animais para consumo humano antes do término do período de carência necessário, após a última aplicação do fármaco. Este fato revela um manejo inadequado da antibioticoterapia de vacas em lactação, particularmente quando empregado no tratamento de mastites (Folly, 2001; Villa, 2007).

Diferentes tipos de riscos estão implicados na problemática da presença de antimicrobianos em leite, tais como os microbiológicos, os imunopatológicos e os toxico farmacológicos. Os microbiológicos consistem basicamente na seleção de cepas resistentes, comprometendo o desequilíbrio da flora intestinal e tratamentos médicos futuros no homem. A maioria da população humana é frequentemente exposta a baixas doses desse tipo de resíduo, o que pode ter efeitos graves a longo prazo. O surgimento de resistência a antimicrobianos em bactérias traz grandes obstáculos a procedimentos médicos tanto em humanos quanto em animais, resultando em aumento das taxas de mortalidade e morbidade na população e dos custos de tratamento de várias enfermidades. Tanto as drogas de uso terapêutico consagrado quanto aquelas de inserção recente no mercado de fármacos vêm se tornando ineficientes no combate a determinadas bactérias (Costa, 2009; Martin, 2011).

Os riscos imunopatológicos encaixam as reações de hipersensibilidade que mesmo sendo raras podem acontecer, ocorrendo choques anafiláticos em indivíduos que sejam sensíveis (Rodrigues et al., 2012). Alterações no processo fermentativo 
industrial pois as culturas lácteas utilizadas são mais sensíveis aos antimicrobianos impedindo uma fermentação de forma satisfatória. Esses resíduos podem ainda apresentar potencial teratogênico, causar doenças sanguíneas e também interferir nos resultados de testes de análise de qualidade do leite diminuindo a contagem bacteriana do leite contaminado (Costa, 2009).

O objetivo deste trabalho foi de determinar se o leite UHT e o leite comercializado de forma informal nas feiras e estabelecimentos comerciais da cidade de Rolim de Moura, Rondônia, possuem resíduos de antibióticos.

\section{Material e Métodos}

Esse estudo foi realizado no município de Rolim de Moura na Zona da mata Rondoniense. O município possui uma área de $1.457,888 \mathrm{~km}^{2}$ com uma densidade demográfica de $34,74 \mathrm{hab} / \mathrm{km}^{2}$ e uma população estimada de 54.702 . Vizinho dos municípios de Santa Luzia d'Oeste, Novo Horizonte do Oeste e Alta Floresta d'Oeste, Rolim de Moura se situa a 49 km a SulOeste de Cacoal. Situado a 232 metros de altitude, com as seguintes coordenadas geográficas: Latitude: $11^{\circ} 43^{\prime} 48^{\prime \prime}$ Sul, Longitude: $61^{\circ} 46^{\prime}$ 47" Oeste. 4.2 .

Amostras Foram obtidas 99 amostras, sendo seis de leite UHT (Ultra High Tempera-ture), duas amostras de cada marca e de lotes diferentes coletadas em estabelecimentos de Rolim de Moura e 93 de leite in natura coletados em feiras comerciais e estabelecimentos da cidade no período de um mês sendo coletadas amostras todos os dias durante este período em vários pontos de feira e estabelecimentos de pequeno porte nos bairros da cidade. As amostras foram congeladas e processadas uma vez por semana durante quatro semanas. As amostras coletadas nas feiras dependiam de quantos produtores estavam presentes e quais feiras alguns deles faziam, ou seja, em algumas amostras o tempo de coleta foi espaçado não sendo coletado leite do mesmo produtor todos os dias.

As amostras foram processadas no laboratório de Microbiologia de uma universidade da cidade de Rolim de Moura. Foi utilizado para análise das amostras um kit comercial Charm ${ }^{\circledR}$ Cowside II Test, que utiliza o método colorimétrico, qualitativo para avaliar a presença de antibióticos em leite cru ou UHT este teste detecta as seguintes classes de medicamentos: betalactâmicos, sulfonamidas, tetraciclinas, macrolídeos e aminoglicosídeos, podendo detectar até 11 medicamentos. Este teste é baseado na inibição do crescimento bacteriano, nos poços contém um ágar com bactérias que em contato com o leite normal crescem e modificam a cor do meio através da produção de ácidos para amarelo e se o leite apresentar resíduos antibióticos o crescimento é inibido permanecendo com a cor inicial do meio que é roxo ou purpura.

A técnica exigida para realizar o teste consiste em primeiro deve individualizar os testes um frasco para cada amostra identificando os frascos por números correspondentes ao da amostra testada, homogeneizar as amostras e inserir a pipeta de $100 \mu l$ abaixo da espuma do leite e dispensar a amostra no tubo do teste contendo o ágar roxo, depois de dispensar todas amostras colhidas no teste deve ser levado em banho maria à $64.0 \pm 0.5^{\circ} \mathrm{C}$ durante 3 horas. Após o teste concluído deve ser feita a leitura do teste sendo a cor roxa para positivo e a cor amarela para negativo o teste também possui uma terceira opção de leitura que é a cor azul ou esverdeado que seria inconclusivo que indica a necessidade de um segundo para confirmação.

\section{Resultados e Discussão}

No presente estudo 99 amostras foram analisadas e foram encontrados 17 resultados positivos que equivale a 17,17\% das amostras sendo nove de leite in natura coletados em estabelecimentos comerciais, cinco em feiras comercias e três de leite UHT demonstrado nos quadros (Quadros 1, 2, 3). Os resultados foram organizados por local de coleta Feira comercial de Rolim de Moura, estabelecimentos comerciais de Rolim de Moura (mercados) e Marca para o Leite UHT contabilizados com número de amostras por produtor, estabelecimento, marca e número de positivos. Para efetuar o quadro os produtores feirantes e estabelecimentos que comercializam leite informal e UHT foram numerados assim como as marcas coletadas. 
Quadro 1 - Resultados de leite in natura coletados em feiras comerciais de Rolim de Moura, Rondônia, Separando-os em: Produtores, $\mathrm{N}^{\circ}$ de amostras e, Resultados positivos.

\begin{tabular}{|c|c|c|}
\hline \multicolumn{2}{|c|}{ Quadro de resultados de leite in natura coletados na feira } \\
\hline Produtores & $\mathbf{N}^{\mathbf{0}}$ de amostras & Resultados positivos \\
\hline Produtor 1 & 8 & 3 \\
\hline Produtor 2 & 4 & 0 \\
\hline Produtor 3 & 13 & 0 \\
\hline Produtor 4 & 4 & 0 \\
\hline Produtor 5 & 10 & 1 \\
\hline Produtor 6 & 1 & 0 \\
\hline Produtor 7 & 4 & 0 \\
\hline Produtor 8 & 2 & 0 \\
\hline Produtor 9 & 2 & 0 \\
\hline Produtor 10 & 3 & 0 \\
\hline Produtor 11 & 2 & \\
\hline Produtor 12 & 3 & \\
\hline Produtor 13 & 1 & \\
\hline Produtor 14 & 1 & 0 \\
\hline Total & 58 & \\
\hline
\end{tabular}

Fonte: Autores.

Quadro 2 - Resultados de leite UHT coletados em Mercados Locais de Rolim de Moura, Rondônia, separando-os em: Marcas de Leite, $\mathrm{n}^{\circ}$ de amostras e, Resultados positivos.

\begin{tabular}{|c|c|c|}
\hline \multicolumn{2}{|c|}{ Quadro de Resultados de leite UHT coletados em Mercados Locais de Rolim de Moura } \\
\hline Marcas de Leite & N $^{\text {o de amostras }}$ & Resultados positivos \\
\hline Marca 1 & 2 & 0 \\
\hline Marca 2 & 2 & 2 \\
\hline Marca 3 & 2 & 3 \\
\hline TOTAL & 6 & 1 \\
\hline
\end{tabular}

Fonte: Autores.

Quadro 3 - Resultados de leite in natura coletados em pequenos mercados de bairros de Rolim de Moura, Rondônia, separandoos em: Estabelecimentos, $\mathrm{n}^{\circ}$ de amostras e, Resultados positivos.

\begin{tabular}{|c|c|c|}
\hline \multicolumn{2}{|c|}{ Quadro de resultados de leite in natura coletados em mercados } \\
\hline Estabelecimentos & $N^{0}$ de amostras & Resultados positivos \\
\hline Estabelecimento 1 & 7 & 0 \\
\hline Estabelecimento 2 & 5 & 1 \\
\hline Estabelecimento 3 & 6 & 4 \\
\hline Estabelecimento 4 & 8 & 1 \\
\hline Estabelecimento 5 & 4 & 1 \\
\hline Estabelecimento 6 & 5 & 9 \\
\hline Total & 35 & 2 \\
\hline
\end{tabular}

Fonte: Autores. 
Este estudo teve resultados bem próximos aos resultados obtidos por Costa et al.(2017) que analisaram 71 amostras de leite in natura coletados em tanques comunitários e particulares da região do município de Marilia- SP que obteve $12,7 \%$ de suas amostras positivas para a presença de $\beta$ - Lactâmicos considerando o clima local diferente, quantidade de amostras diferentes tipos de amostragem bem distinta os resultados obtidos ainda se assemelham muito ao do presente trabalho que indica que há uma incidência comum ao uso de antibióticos em várias regiões do país.

Um outro estudo realizado por Silva et al. (2016) analisaram 80 amostras de leite pasteurizado em Londrina - PR e encontraram 13 (16, 25\%) amostras em desacordo com a legislação destas três ( 3,75\%) foram resultados positivos e dez (12,5\%) consideradas suspeitas para a presença de antibióticos essas amostras foram obtidas leite pasteurizado em um laticínio e comercializado no município, este estudo analisou apenas leite pasteurizado que o diferencia do presente estudo e indica que mesmo em leites que não são considerados informais ainda são encontrados esses resíduos em altas quantidades.

Segundo Silva et al. (2014) em um estudo que analisaram 50 amostras de tanques de refrigeração da mesorregião sul paraense (Conceição do Araguaia, Redenção, Rio Maria e Xinguara) onde houve apensas quatro (8\%) amostras positivas este estudo foi realizado utilizando o kit comercial Delvotest ${ }^{\circledR}$ que é bem semelhante ao kit utilizado no presente estudo. No trabalho teve um percentual bem baixo de positivos, o presente estudo teve um índice de positivos maior o que pode ter acontecido e que os números de positivos podem ser afetados pelas coletas que foram realizadas em taques de refrigeração de três a cinco mil litros de capacidade que continham leite de vários produtores que os utilizavam coletivamente o que dava ao estudo uma ampla amostragem de vários produtores e também uma dificuldade maior por se tratar de leites de diferentes propriedades e os antibióticos poderiam estar diluídos tendo em consideração que o teste tem uma concentração mínima para dar positivo.

Em um experimento realizado por Neto et al. (2015) foram testadas terapias no pré parto onde foram utilizados 47 animais de propriedades leiteiras, oriundas do estado de Rondônia, para tratamentos com antibióticos comerciais antimastíticos específicos para uso em período seco (cloxacilinabenzatina e espiramicina em associação com neomicina) e em lactação (cloridrato de ceftiofur) aos 60 e 30 dias pré-parto, respectivamente, em uma única aplicação.

As análises para detecção de resíduos de antimicrobianos foram realizadas com um teste microbiológico comercial Eclipse 50 (ZEU-Inmunotec $®$, Zaragoza). Foi constatada a presença desses em 3,44\% dos animais tratados com cloxacilina, em $12,50 \%$ dos animais tratados com espira-micina associada à neomicina e em 10\% dos animais que receberam cloridrato de ceftiofur. O período para o aproveitamento do leite após a terapia de vacas secas com antibióticos mais indicado foi de 30 dias para antibióticos usados durante a lactação e de 60 dias para tratamento de vacas secas, essa terapia indica que o aparecimento de resíduos antibióticos no leite pode não estar sendo causada apenas pela adulteração ou mau uso do medicamento e sim por uma falha do laboratório nas especificações de tempo de carência.

Uma revisão bibliográfica feita por Caselani (2014) de estudos sobre resíduos medicamentosos em produtos de origem animal encontrou um dado de uma pesquisa realizada com 79 amostras de leite pasteurizado tipo B no Paraná, que teve um resultado bem aproximado ao obtido no trabalho com 19\% amostras positivas onde a maioria das amostras apresentava resíduos por dois tipos de antibióticos simultaneamente considerando que o número de amostras colhidas são menores que do presente trabalho o número de positivos se torna ainda mais substancial demonstrando a dificuldade em controlar esses resíduos nos produtos de origem animal.

Segundo Magnavita (2012), que realizou um estudo onde foram analisadas 240 amostras de leite pasteurizado tipo integral de 20 marcas diferentes, coletando amostras mensalmente no período de 12 meses em estabelecimentos comerciais da região Sul e Sudoeste do estado da Bahia, essas amostras foram analisadas pelo teste Delvotest ${ }^{\circledR}$ como teste de triagem e depois utilizou o método de cromatografia para quantificar e identificar os resíduos nas amostras. Dessas amostras 19 (7,9\%) foram consideradas positivas de acordo com o teste de triagem 24 (10\%) foram consideradas suspeitas e 197 negativas para a presença de antibióticos, o período de frequência de amostras positivas e com suspeita de resíduos foi mais observado nos meses de janeiro 
a junho esse período foi ligado ao clima do local de estudo que indica uma maior incidência de casos de mastites nessa época do ano.

Das 20 marcas analisadas apenas quatro não apresentaram nenhuma amostra positiva. Os efeitos climáticos do estudo foram muito importantes assim como os métodos utilizados para avaliar as amostras seus resultados apresentam um índice um tanto inferior ao presente trabalho embora seus métodos de amostras quantidades e métodos de análise sejam completamente diferentes mas demostram resultados significativos que indicam que há uma necessidade de maior investigação desses resíduos também na região de Rolim de Moura por haverem quantidades maiores de resultados positivos na região.

De acordo com Borges et al. (2000) no período de junho 1997 a agosto de 1998 analisaram 533 amostras de leite integral padronizado de 98 marcas diferentes em Goiás utilizando um método baseado na difusão do resíduo antimicrobiano em ágar, tendo o Bacillus subtilis e o Bacillus stearothermophilus como "microrganismos testes". Obteve em seus resultados 53 ( 9,95\%) amostras positivas esses resultados são muito intrigantes pois com eles constata-se que a antibioticoterapia vem aumentando a cada década considerando que esse estudo foi feito a 22 anos atrás em comparação ao presente estudo e com ela a incidência de resíduos tem aumentado mesmo com iniciativas como o PAMVET que aumenta a fiscalização desses resíduos, isso provavelmente ocorre devido a maior facilidade em encontrar esses produtos no mercado e talvez também a maior incidência de casos de mastites que são diagnosticadas.

Segundo Vidal-Martins et al. (2013) que realizaram uma pesquisa entrevistando 855 consumidores sobres suas preferencias em relação ao consumo de leite na região de São Paulo que obteve resultados alarmantes pois 31,18\% afirmaram preferir comprar leite de forma informal sem fiscalização alegando que o motivo da preferência seria acreditar ser um leite mais saudável sem adição de conservantes ou até mesmo mais fresco e saboroso. Ainda nessa entrevista foi perguntado aos consumidores se o leite poderia transmitir doenças que obteve um resultado de 65,96\% alegaram que "Não" e um número de 34,03\% afirmaram que "Sim" embora quando questionados sobre qual doença alegaram ser a Febre aftosa que é uma doença não zoonótica esses dados se tornam relevantes por observar a total ignorância dos consumidores sobre os produtos que consomem e sobre o risco que eles apresentam a sua saúde em relação a doenças que é algo tão estudado imagina-se que em relação a presença de antibióticos provavelmente os dados sejam ainda mais desconhecidos pela população levando a considerar a im-portância de conscientizar o risco que esses resíduos podem causar a saúde e assim diminuir o consumo de leite sem fiscalização.

Rodrigues et al. (2012), que fizeram um levantamento da presença de resíduos antibióticos da região de Campos Gerais no Paraná após a implantação de política de pagamento quanto ao requisito ausência de inibidor, analisaram 400 produtores durante cinco anos no período de 2005 a 2010 que totalizou 72 amostras de cada produtor e obtiveram o seguintes resultados: ano de 2005 (35\%) das amostras positivas, 2006 (29\%), 2007 (29\%), 2008 (27\%), 2009 (23\%), 2010 (12\%) esses resultados indicam que a frequência no aparecimento de resíduos diminui quando se institui programas de incentivo, trabalhos educativos e programas de qualidade algo que já deveria estar sendo instituído no estado de Rondônia a alguns anos para incentivar os produtores a produzirem com melhor qualidade.

Freitas et al. (2017) realizaram um experimento que testou 750 amostras de leite de um laticínio localizado em Patos de Minas- MG utilizando kit do teste SNAPduo Beta-Tetra ST no período de junho de 2017, o leite foi coletado nos fornecedores conforme a normativa 62 prevê para coleta e transporte de leite como resultado obteve apenas uma amostra positiva de um tanque contendo 1350 litros de leite esse trabalho traz algumas informações interessantes que indicam que o controle de resíduos antibióticos no leite e possível no estudo a autora atribuiu a diminuição da frequência de resíduos a uma política estabelecida pelo laticínio que impede a reincidência de envio de leite contaminado por resíduos devido à separação de animais em período de tratamento com antibióticos. Já na região de Rolim de moura parece ainda não haver nenhuma política semelhante 
principalmente nos produtos de venda informal que não se tem controle e fiscalização adequados para instituir políticas de boas práticas e conscientizar os produtores e consumidores dos riscos que os resíduos causam a saúde.

\section{Conclusão}

Com este estudo pode-se observar a presença de resíduos antibióticos em leite comercializado de forma informal em Rolim de Moura - RO. Na região não se tem o controle adequado desses resíduos e também não há políticas que instituam conhecimento aos produtores e aos consumidores ou até mesmo políticas de incentivo à produção de leite de boa qualidade.

\section{Referências}

Almeida, F. M. (2016). Qualidade de leite bovino produzido em propriedades de agricultura familiar, cacoal/ro. 54 f. Dissertação (Mestrado em Produção Animal) - Universidade Camilo Castelo Branco, Descalvado.

ANVISA. (2009). Programa de Análise de Resíduos de Medicamentos Veterinários em alimentos de Origem Animal - PAMVet -Relatório 2006/2007 Monitoramento de Resíduos em Leite Exposto ao Consumo ( $5^{\circ}$ e $6^{\circ}$ anos de atividades).

Borges, G. T. et al. (2000). Ocorrência de resíduos de antibióticos em Leite pasteurizado integral e padronizado produzido e comercializado no estado de Goiás. Ciência Animal Brasileira, 1: 59-63.

Brasil. (2017). Decreto $n^{o}$ 9.013, de 29 de março de 2017. Das disposições preliminares e do âmbito de atuação. <https://www.saude.rj.gov.br/comum/code/MostrarAr-quivo.php?C=NzU2NQ\%2C\%2C>.

Caselani, K. (2014). Resíduos de medicamentos veterinários em alimentos de origem animal. Arquivo Ciência Veterinária Zoologia UNIPAR, 17(3): 189-197.

Colville, T. \& Bassert, J. M. (2010). Anatomia e fisiologia clínica para medicina veterinária. (2a ed.).

Costa, G. M. et al. (2013). Resistência a antimicrobianos em Staphylococcus aureus isolados de mastite em bovinos leiteiros de Minas Gerais, Brasil. Arquivo Instituto de Biologia, 80(3): 297-302.

Costa, A. B. L. et al. (2017). Avaliação de resíduos de antibióticos em leite cru produzido na região de Marília. Unimar Ciências, 26(1-2): 114-123.

Costa, A. S. (2009). Avaliação da Presença de Resíduos de Antimicrobianos em Leite e Bebida Láctea UHT por Teste de Inibição Microbiana Comercial. 73f. Dissertação (Mestrado em Ciência e Tecnologia de Alimentos), Universidade Federal Rural do Rio de Janeiro, Seropédica.

EMBRAPA. (2011). Avaliação da qualidade composicional e da saúde da glândula mamária de rebanhos bovinos localizados na bacia leiteira de Ji-Paraná e Rolim de Moura, Rondônia. Comunicado técnico num 366. Porto Velho, julho de 2011.

EMBRAPA. (2014). Qualidade do leite armazenado em tanques de resfriamento de Rondônia. Comunicado técnico num. 393 . Porto Velho, Rondônia.

Folly, M. M. \& Machado, S. C. A. (2001). Determinação de resíduos de antibióticos, utilizando-se métodos de inibição microbiana, enzimático e imunoensaios no leite pasteurizado comercializado na região norte do estado do rio de janeiro, Brasil. Ciência Rural, 31(1): 95-98.

Freitas, C. R. et al. (2017). Análise da ocorrência de resíduos de antibióticos em leite proveniente de propriedades em Patos de Minas -MG. Revista Agroveterinária, Negócios e Tecnologias, 2(2): 08-25.

Gasparotto P. H. G. et al. (2016). Principais gêneros bacterianos causadores de mastite isolados no Laboratório de Microbiologia Veterinária do Hospital Veterinário do Centro Universitário Luterano de Ji-Paraná/RO. Veterinária em foco, 14(1): 60-74.

Hill, R. W., Wyse, G. A. \& Anderson, M. (2012). Fisiologia Animal. (2a ed.), <https://books.google.com.br/books?hl=pt-BR\&lr=\&id=DklCDQAAQBAJ\&oi=fnd\&pg=PR1\&dq=fisiologia+animal\&ots=CrqyDFLaid\&sig=YKiVe6kmSx-mpV5P4EEU4CAfEAfo\#v=onepage \&q\&f=false .

IBGE. (2018). Bovino/Leite de vaca/Quantidade produzida. <https://www.milkpoint.com.br/noticias-e-mercado/panorama-mercado/ibge-producao-total-deleite-cai-05-em-2017-210514/>.

Jung, C. F. \& Júnior, A. A. M. (2017). Produção leiteira no Brasil e características da bovinocultura leiteira no Rio Grande do Sul. Ágora, 19(1): 34-47.

König, H. E. \& Liebich, H. G. (2016). Anatomia dos Animais Domésticos: Texto e Atlas Colorido. (6a ed.), <https://books.google.com.br/books?hl=ptBR\&lr=\&id=Vi1fDAAAQBAJ\&oi=fnd\&pg=PR1\&dq=Anatomia +de+grandes+animais\&ots=wVgAP5EBLa\&sig=XjhI5ZDOF6dVR4oVbXx9plIPOGo\#v=o ne-page $\& q \& \mathrm{f}=$ false $>$.

Magnavita, A. P. A. (2012). Avaliação das características físico-químicas e da presença de resíduos de antimicrobianos em leite pasteurizado nas regiões Sudoeste e Sul Baiano. 68 f. Dissertação (Mestrado em Engenharia de alimentos) -Universidade Estadual do Sudoeste da Bahia, Itapetininga-BA.

Martin, J. G. P. (2011). Resíduos de antimicrobianos em leite - uma revisão. Segurança Alimentar e Nutricional, $18(2)$ : 80-87. 
Research, Society and Development, v. 11, n. 2, e38811221804, 2022

(CC BY 4.0) | ISSN 2525-3409 | DOI: http://dx.doi.org/10.33448/rsd-v11i2.21804

Neto, A. E. et al. (2015). Avaliação de resíduo de antibiótico em amostras de leite de vacas após aterapia de vacas secas. Arquivo do Instituto Biológico, 82: 14

Rodrigues, M. X., Agnoll. D. \& Bittencourt, J. V. M. (2012). Levantamento da Ocorrência de Resíduos de Antibióticos em Leite Cru Produzido na Região dos Campos Gerais, Paraná. UNOPAR Cientifica Ciências Biológicas e da Saúde, 14(4).

SEBRAE. (2015). Diagnóstico do Agronegócio do Leitee Derivados do Estado de Rondônia.

Silva, D. P. et al. (2014). Ocorrência de resíduos de antibióticos em leite de células de refrigeração da região Sul do estado do Pará - Brasil. Revista Brasileira de Produtos Agroindustriais, 16(4): 359-368.

Silva, M. H. et al. (2016). Detecção de resíduos deantibióticos e de substâncias antimicrobianas em leite pasteurizado. I CONGRESSO NACIONAL DE $\begin{array}{lllllll}P E S Q U I S A & E & E N S I N O & \text { CIENNCIA, } & \text { Campina } & \text { Grande-PB, }\end{array}$ 〈https://www.editorarealize.com.br/revistas/conapesc/trabalhos/TRABALHO_EV058_MD4_SA80_ID1270_08052016111528.pdf〉.

Vidal-Martins, A. M. C. (2013). Avaliação do consumo de leite e produtos lácteos informais e do conhecimento da população sobre os seus agravos à saúde pública, em um município do es-tado de São Paulo, Brasil. Boletim de Indústria Animal, 70(3): 221-227.

Villa, F. B. (2007). Qualidade fisico-químico, microbiológica e resíduos de antimicrobianos em leite in natura comercializado informalmente em brotas, SP. 58f. Dissertação (mestrado) - Universidade Estadual Paulista, Faculdade de Medicina Veterinária e Zootecnia, Botucatu.

Vilela, D. et al. (2017). A evolução do leite no Brasil em cinco décadas. Política agrícola, 26(1): 5-24. 